\title{
Retraction
}

\section{Retracted: A Simple and Accurate Interpretation Method of In Situ Stress Measurement Based on Rock Kaiser Effect and Its Application}

\author{
Geofluids Editorial Board \\ Received 5 May 2022; Accepted 5 May 2022; Published 3 August 2022 \\ Copyright ( 92022 Geofluids Editorial Board. This is an open access article distributed under the Creative Commons Attribution \\ License, which permits unrestricted use, distribution, and reproduction in any medium, provided the original work is \\ properly cited.
}

Geofluids has retracted the article titled "A Simple and Accurate Interpretation Method of In Situ Stress Measurement Based on Rock Kaiser Effect and Its Application" [1], due to similarity identified with a previous publication. The authors initially contacted the journal to request a correction to the article to add the citation and an accompanying discussion, however, the editorial board feel that a retraction of the article is required. This is because both articles use the cumulative ringing counts-time curve to determine the Kaiser point and this method is the primary idea of both papers.

The authors agree to the retraction and the notice.

\section{References}

[1] K. Zhao, G. Shuijie, Y. Yan, K. Zhou, Q. Li, and S. Zhu, "A Simple and Accurate Interpretation Method of In Situ Stress Measurement Based on Rock Kaiser Effect and Its Application," Geofluids, vol. 2018, 13 pages, 2018. 


\title{
A Simple and Accurate Interpretation Method of In Situ Stress Measurement Based on Rock Kaiser Effect and Its Application
}

\author{
Kang Zhao ${ }^{D},{ }^{1,2,3}$ Shuijie Gu, ${ }^{1}$ Yajing Yan, ${ }^{1}$ Keping Zhou, ${ }^{2}$ Qiang Li, ${ }^{1}$ and Shengtang Zhu ${ }^{1}$ \\ ${ }^{1}$ School of Architectural and Surveying \& Mapping Engineering, Jiangxi University of Science and Technology, \\ Ganzhou 341000, China \\ ${ }^{2}$ School of Resources and Safety Engineering, Central South University, Changsha, Hunan 410083, China \\ ${ }^{3}$ Jiangxi Provincial Key Laboratory of Geotechnical Engineering and Environmental Disaster Control, Ganzhou 341000, China
}

Correspondence should be addressed to Kang Zhao; zhaok_666666@163.com

Received 12 March 2018; Accepted 7 May 2018; Published 7 June 2018

Academic Editor: Qingsheng Bai

Copyright (c) 2018 Kang Zhao et al. This is an open access article distributed under the Creative Commons Attribution License, which permits unrestricted use, distribution, and reproduction in any medium, provided the original work is properly cited.

Many deep underground excavation practices show that the size and distribution of in situ stress are the main factors resulting in the deformation and instability of the surrounding rock structure. The in situ stress measured by the Kaiser effect of rock is used by engineers because of its economy and convenience. However, due to the lack of quantitative judgment basis in determining the Kaiser point position, there is a large artificial error in the practical application. In response to the problem, this study systematically investigates the characteristics of rock acoustic emission curve on the basis of the fractal theory and establishes an accurate and simple interpretation method for determining the Kaiser point position. The indoor rock acoustic emission test was carried out by drilling a rock sample at a mine site. By using the conventional tangent method, the cumulative ringing count rate-time-stress curve of rock acoustic emission is analyzed to preliminarily determine the time range of Kaiser point appearance. Considering that the fractal dimension of the rock Kaiser point is lower than the adjacent point, the minimum point of the fractal dimension of this time range can be determined from the fractal dimension-time-stress curve. Such determined point is the Kaiser point. The size of the in situ stress is calculated using an analytical method. Based on the value of the in situ stress, the distribution of the in situ stress in the mining area is further analyzed using the geological structure of the mine. The maximum principal stress is $19.38 \mathrm{MPa}$, with a direction of $\mathrm{N}\left(30^{\circ}-40^{\circ}\right) \mathrm{E}$, and the minimum principal stress is 8.02 $\mathrm{MPa}$ with a direction of $\mathrm{N}\left(50^{\circ}-60^{\circ}\right) \mathrm{W}$. The maximum and minimum principal stresses are approximately in the horizontal plane. The intermediate principal stress is $11.73 \mathrm{MPa}$ in vertically downward. These results are basically consistent with the distribution statistical law of the measured in situ stress fields in the world. The results presented in the study could provide a reference for the later mining, stability evaluation, and support of the surrounding rock.

\section{Introduction}

As the original undisturbed stress in the rock, in situ stress is one of the most important factors affecting the stability of underground excavation engineering and many researches have been done [1-3]. The study of in situ stress measurement in a deep mine by Kang et al. provided the basic parameters for the layout and support design of a deep roadway [4]. Komurlu et al. studied the effect of horizontal in-situ stress on the failure mechanism around underground openings excavated in isotropic, elastic rock zones [5]. Lin et al. studied the deformation, cracking and failure mechanism, and the overall stability of the deep buried tunnel with high in situ stress for designing optimal support system [6]. In situ stress is the fundamental force causing the deformation and destruction of mining, water conservancy and hydropower, civil engineering, and other underground rock excavation engineering. It is a necessary prerequisite to determine the mechanical properties of engineering rock mass, analyze the stability of surrounding rock, and realize the scientific design of rock excavation and decisionmaking [7]. With the continuous expansion of the scale 
and depth of mine excavation, in situ stress has become more prominent and the occurrence of many disaster phenomena is closely related to the in situ stress [8-10]. Therefore, it is necessary to determine the distribution of the in situ stress before the mining project. The rational layout of the roadway can not only improve the safety and avoid the occurrence of disaster but also reduce the cost of support and maintenance.

At present, there are many in situ stress measurement methods, which can be divided into two categories: direct measurement method and indirect measurement method $[11,12]$. In the direct method, only the hydraulic fracturing method and the acoustic emission method do not require preexcavation of the chamber, which is relatively more convenient and quick. The hydraulic fracturing method is to estimate the stress field of the measuring point on the spot after drilling to the measuring point. This method is expensive due to the bulky hydraulic fracturing vehicle and expensive measuring instruments. The acoustic emission method only needs to obtain the rock core of the corresponding measuring point, and the Kaiser effect of the rock can be used to estimate the in situ stress. Due to a simple and convenient operation, low price, less on-site operation, and suitability for indoor large-scale batch testing, the acoustic emission method is more widely used in mines [13, 14], oil fields $[15,16]$, and tunnel traffic $[17,18]$.

Although the interpretation of the Kaiser point is the key to the acoustic emission method for in situ stress measurement, there are still some deficiencies in the interpretation of the Kaiser point, which seriously hinders the wide application of the method. At present, the interpretation of the Kaiser point is based on the sudden increase of data on a parameter or on the slope of the curve. There is no standard for the quantitative evaluation of this kind of change, and it lacks a scientific basis. When the change is not clear, it is difficult to control the error of manual interpretation. Therefore, it is in need to propose a method to determine the location of the Kaiser point through quantitative evaluation criteria. In this paper, the indoor rock acoustic emission test was carried out by drilling a rock sample at a mine site. According to the accurate and convenient interpretation method of the Kaiser point, the test results are studied and analyzed. Finally, the size and distribution law of in situ stress in this mine are obtained. The result can provide basic data for the mining design, roadway support, and stability evaluation of the surrounding rock in the later stage of mining and provide the guarantee for the high efficiency and safe production of the mine.

\section{Principle of Acoustic Emission Testing}

Under the action of an external load, the stress concentration inside the material will form damage, which will lead to the release of energy stored in the material. The stress waves were released from the phenomenon of acoustic emission. In 1950, German Kaiser discovered that there was a lot of acoustic emission phenomenon once the applied load exceeded the historical maximum stress level of metallic materials. This phenomenon is called the

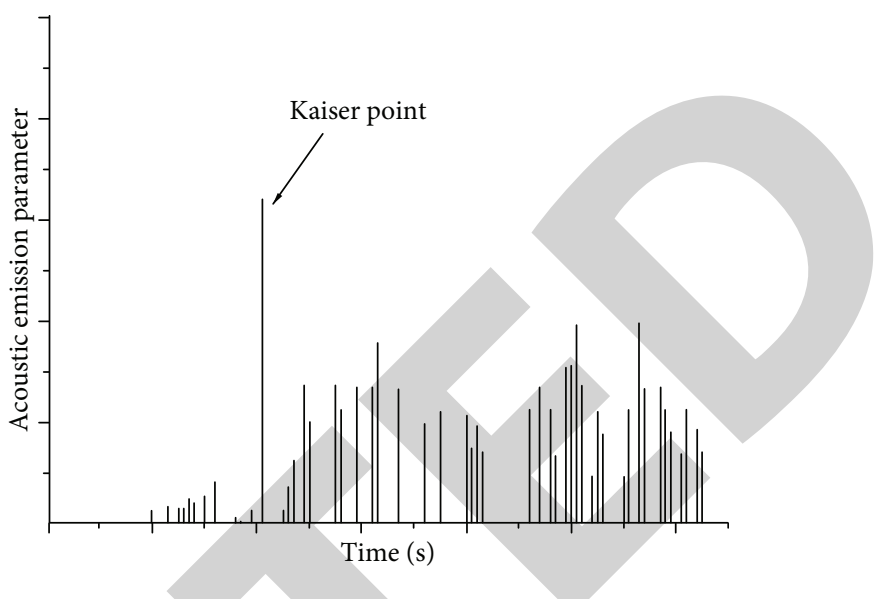

FIgURE 1: Kaiser point interpretation of acoustic emission parameters.

Kaiser effect. The point of transition from a small amount of acoustic emission to a large amount of acoustic emission is called the Kaiser point, and the stress corresponding to this point is the maximum historical stress of the material. Later, many people proved by experiments that a rock also has such a significant Kaiser effect [19-21]. Therefore, as long as the directional rock core is taken back from the original rock for an indoor test, the original rock stress can be obtained by using the Kaiser effect.

\section{Interpretation of Kaiser Point}

3.1. Shortcomings of Kaiser Point Interpretation Method. The interpretation of the Kaiser point is the key to the acoustic emission method for in situ stress measurement. Now, the interpretation of the Kaiser point is usually determined by the sharp change of one or more parameters of acoustic emission signals to determine the location of Kaiser points. There are two kinds of conventional interpretation methods. One is the direct interpretation of the relationship between a parameter and time by acoustic emission, as shown in Figure 1. The basis of this method is whether there is a large amount of acoustic emission after a certain time point. However, there is no quantitative standard for the large quantity of acoustic emission and the interpretation has a certain subjectivity. It is difficult to grasp the accuracy in application.

Another method is to interpret the sharp change point of the change rate of the relation curve between the cumulative parameter and the time of acoustic emission. The method is easier to interpret for a curve with a significant inflection point, as shown in Figure 2. When the inflection point of the accumulated parameter is ambiguous, the tangent is used to assist the interpretation and the intersection point of the tangent is determined as the Kaiser point, as shown in Figure 3.

The above two methods for the interpretation of the Kaiser point are based on the sudden increase of data on a parameter or the sudden increase of the slope of the curve. There is no quantitative evaluation of this kind of change. When the change is not obvious, it is difficult to control the 


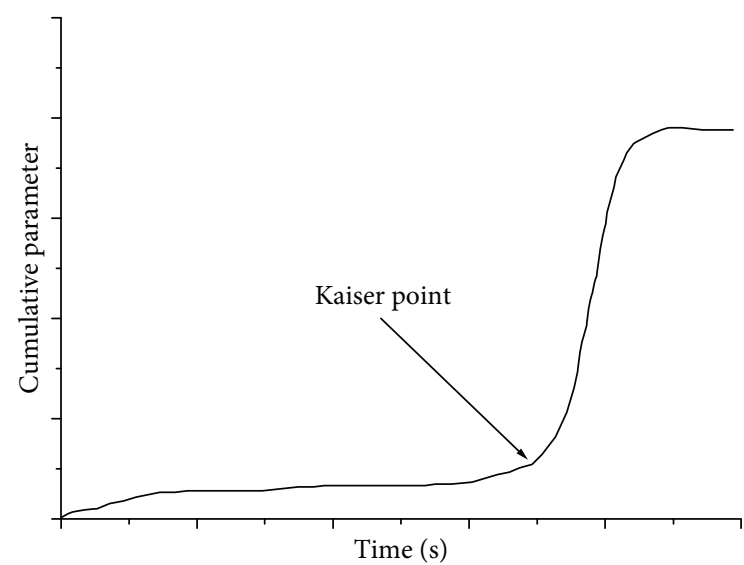

FIGURE 2: Kaiser point interpretation of the inflection point of the accumulated parameter.

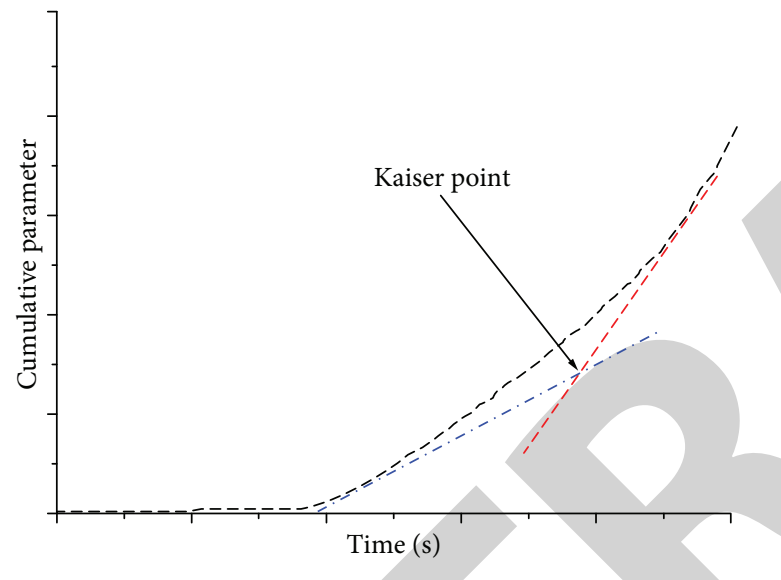

FIGURE 3: Kaiser point interpretation of the cumulative parameter curve of the fuzzy inflection point.

error of manual interpretation. Therefore, it is of great significance to propose a method to determine the location of the Kaiser point through quantitative evaluation criteria.

3.2. Comprehensive Analysis Method of Kaiser Point Interpretation. At present, the determination of the Kaiser point is mainly based on the acoustic emission characteristic curve. By analyzing and comparing different characteristic parameter curves, the clear degree of the Kaiser point is as follows: acoustic emission cumulative energy-time curve $>$ acoustic emission cumulative ringing count-time curve $>$ acoustic emission cumulative event-time curve. However, when the Kaiser point is intuitively judged by the mapping method, the acoustic emission cumulative energy-time curve may have multiple mutation points. These interference points will have a greater impact on the accuracy of the interpretation results, while the acoustic emission cumulative ringing count-time curve is less affected by this. After comprehensive consideration, the cumulative ringing count rate-time-stress curve is used to estimate the Kaiser point.

In addition, due to the unavoidable noise interference during the acoustic emission signal acquisition. In order to further reduce the impact of interference signals on the cumulative ringing rate-time curve, it is necessary to denoise the ringing count time sequence of acoustic emission before data analysis. After thorough research, the wavelet analysis method is used to extract the useful original signal from the acoustic emission signal containing various noises, which can improve the signal-noise ratio and restore more authentic acoustic emission signal data. At the same time, different types of wavelet functions are compared and analyzed according to the characteristics of rock acoustic emission signals. Finally, the noise reduction of rock acoustic emission time series is determined by using the Daubechie wavelet family. The noise reduction process is divided into the following three steps:

(1) Wavelet decomposition of the original signal: a signal model with noise can be expressed as

$$
S(j)=f(j)+e(j), \quad j=0,1, k, n-1 .
$$

In the formula, $S(j)$ is the original signal with noise, $f(j)$ is the true signal of rock acoustic emission, and $e(j)$ is the noise signal. The db3 wavelet base is selected by MATLAB software to decompose the acoustic emission original signal into 5 layers.

(2) Threshold quantization of wavelet coefficients with noise: the fixed threshold method is used to denoise, and the threshold $Q$ is $Q=\operatorname{sqrt}[2 \lg (\operatorname{length}(y))]$, where $y$ represents the signal to be analyzed. Comparing the wavelet coefficients with noise and the threshold $Q$ after the wavelet changes, the wavelet coefficients lower than $Q$ become zero, and the wavelet coefficients larger than $Q$ become the difference with $Q$.

(3) The wavelet coefficients which are quantized by threshold quantization are reconstructed to get the signal to remove the noise interference.

Many studies have found that the band energy of the rock Kaiser point is higher than the other nearby points, but the fractal dimension is lower than the adjacent points. According to the characteristics of the rock Kaiser point and the cumulative ringing count rate curve of acoustic emission which has less interference on the interpretation of the Kaiser point, the correlation dimension of the acoustic emission ringing count is used to analyze the fractal characteristics of the rock. Using the method proposed by Grassberger and Procaccia to calculate the correlation dimension of a sequence from time series [22] (hereinafter referred to as the G-P algorithm), the basic parameter sequence of acoustic emission is taken as the object of study and each sequence corresponds to a sequence set with a sample size of $n$ :

$$
X=\left\{x_{1}, x_{2}, x_{3}, \ldots, x_{n}\right\} .
$$

Formula (2) can construct an $m$-dimensional phase space $(m<n)$ and take the number of $\mathbf{m}$ as an $m$-dimensional vector of the sample space:

$$
X_{1}=\left\{x_{1}, x_{2}, x_{3}, \ldots, x_{m}\right\}
$$


Then move one bit backward, take $m$ numbers to form the second vector, and so on, the time series can form a total of $n-m+1 m$-dimensional vectors. The corresponding correlation function is

$$
w[r(k)]=\frac{1}{N^{2}} \sum_{i=1}^{N} \sum_{j=1}^{N} H\left[r(k)-\left|X_{i}-X_{j}\right|\right] .
$$

In the formula, $H$ is the Heaviside function and $r$ is the given scale. In order to control the discreteness of the calculation, results generally take

$$
r(k)=k \frac{1}{N^{2}} \sum_{i=1}^{N} \sum_{j=1}^{N}\left|X_{i}-X_{j}\right| .
$$

In the formula, $k$ is the proportionality coefficient. From the above all kinds of processing through the MATLAB program, you can get a set of scattered points in a given dimension. If these scattered points can form a straight line on $\{\ln W[r(k)], \ln r(k)\}$, it shows that the acoustic emission sequence of the sample has good fractal characteristics in a given dimension and the slope of the regression line is the correlation dimension. The fractal dimension-time-stress curve of each sample is obtained by the above G-P algorithm.

Based on the above theory, a comprehensive analysis method can be proposed to accurately interpret the Kaiser point. First, the time range of the Kaiser point is estimated on the cumulative ringing count rate-time-stress curve by using the conventional tangent method. Then on the fractal dimension-time-stress curve, look for the minimum value of the fractal dimension in this time range, that is Kaiser point. In this way, the position of the Kaiser point can be determined by a quantitative evaluation criterion, which not only has a certain physical meaning but also reduces the error caused by manual interpretation to a certain extent and improves the accuracy of interpretation. The specific steps are as follows:

(1) Use the tangent method to draw the tangent at the cumulative ringing count rate-time- stress curve. The time corresponding to the tangent intersection point is determined to be an approximate Kaiser point time.

(2) Read the time of the minimum value of the fractal dimension over the estimated approximate Kaiser point time range; this time is fixed as the time when the Kaiser point appears.

(3) Pick up the Kaiser point of time, and read the corresponding stress value on the stress-time curve that the stress at this time is the maximum stress level in the axial history of the specimen.

\section{Analytic Calculation Method of In Situ Stress}

The acoustic emission test can measure the axial stress in the core, and because of the directionality of the Kaiser effect, stress levels in many directions can be obtained by

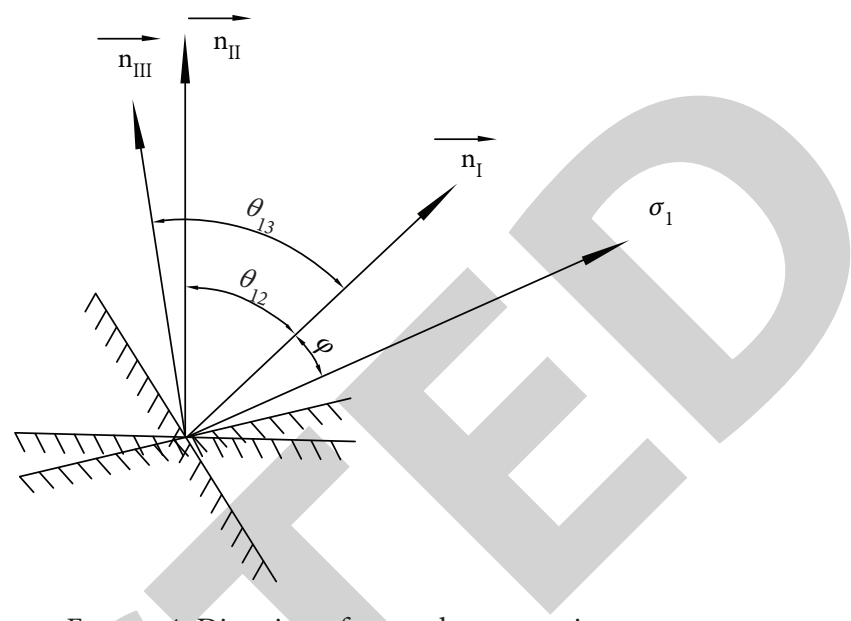

FIGURE 4: Direction of normal cross section.

different coring directions. According to the elastic theory, the stress tensor at any point of the space can be determined by the stress in 6 directions. In fact, many studies have shown that the magnitude and direction of the principal stress can be obtained by the formula transformation based on knowing the normal stress of three different cross sections.

As shown in Figure 4, three known cross sections, the angle between the normal vectors $\overrightarrow{\mathbf{n}}_{\mathrm{I}}$ and $\overrightarrow{\mathbf{n}}_{\mathrm{II}}$ is $\theta_{12}$, and the angle between $\overrightarrow{\mathbf{n}}_{\text {I }}$ and $\overrightarrow{\mathbf{n}}_{\text {III }}$ is $\theta_{13}$.

If the angle between principal stress $\sigma_{1}$ and normal vectors $\overrightarrow{\mathbf{n}}_{\mathrm{I}}$ is $\varphi$, then the solution of principal stress $\sigma_{1}$ and $\sigma_{2}$ is: It is known that the normal stresses $\sigma_{\mathrm{I}}, \sigma_{\mathrm{II}}, \sigma_{\mathrm{III}}$ on the three sections to calculate the magnitude of principal stress $\sigma_{1}$ and $\sigma_{2}$, and the direction $\varphi$ of principal stress $\sigma_{1}$. (The prescribed counterclockwise rotation is positive, and tensile stress is positive.) The relationship between the normal stress $\sigma_{n}$ and the principal stress at any cross section is as follows:

$$
\sigma_{n}=\frac{1}{2}\left(\sigma_{1}+\sigma_{2}\right)+\frac{1}{2}\left(\sigma_{1}-\sigma_{2}\right) \cos 2 \varphi
$$

Thus, the equation can be obtained:

$$
\begin{aligned}
\sigma_{\mathrm{I}} & =\frac{1}{2}\left(\sigma_{1}+\sigma_{2}\right)+\frac{1}{2}\left(\sigma_{1}-\sigma_{2}\right) \cos 2 \varphi, \\
\sigma_{\mathrm{II}} & =\frac{1}{2}\left(\sigma_{1}+\sigma_{2}\right)+\frac{1}{2}\left(\sigma_{1}-\sigma_{2}\right) \cos 2\left(\theta_{12}+\varphi\right), \\
\sigma_{\mathrm{III}} & =\frac{1}{2}\left(\sigma_{1}+\sigma_{2}\right)+\frac{1}{2}\left(\sigma_{1}-\sigma_{2}\right) \cos 2\left(\theta_{13}+\varphi\right) .
\end{aligned}
$$

Formula (7) and (8) simultaneous solution can be obtained:

$\sigma_{1}=\frac{\sigma_{\mathrm{I}}\left(\cos 2 \theta_{12}-\sin 2 \theta_{12} \tan 2 \varphi\right)-\sigma_{\mathrm{II}}-\left(\sigma_{\mathrm{I}}-\sigma_{\mathrm{II}}\right) \sec 2 \varphi}{1-\cos 2 \theta_{12}+\sin 2 \theta_{12} \tan 2 \varphi}$,

$\sigma_{2}=\frac{\sigma_{\mathrm{I}}\left(\cos 2 \theta_{12}-\sin 2 \theta_{12} \tan 2 \varphi\right)-\sigma_{\mathrm{II}}+\left(\sigma_{\mathrm{I}}-\sigma_{\mathrm{II}}\right) \sec 2 \varphi}{1-\cos 2 \theta_{12}+\sin 2 \theta_{12} \tan 2 \varphi}$ 
Substituting formulas (10) and (11) into formula (9) can be obtained:

$\tan 2 \varphi=\frac{\left(\sigma_{\mathrm{II}}-\sigma_{\mathrm{I}}\right) \cos 2 \theta_{13}+\left(\sigma_{\mathrm{III}}-\sigma_{\mathrm{II}}\right)-\left(\sigma_{\mathrm{III}}-\sigma_{\mathrm{I}}\right) \cos 2 \theta_{12}}{\left(\sigma_{\mathrm{II}}-\sigma_{\mathrm{I}}\right) \sin 2 \theta_{13}-\left(\sigma_{\mathrm{III}}-\sigma_{\mathrm{I}}\right) \sin 2 \theta_{12}}$.

Then formula (12) is substituted by (10) and (11); the formulas for calculating the principal stresses $\sigma_{1}$ and $\sigma_{2}$ are obtained.

$$
\begin{aligned}
\sigma_{1}= & \frac{-\sigma_{\mathrm{I}} \sin 2\left(\theta_{13}-\theta_{12}\right)+\sigma_{\mathrm{II}} \sin 2 \theta_{13}-\sigma_{\mathrm{III}} \sin 2 \theta_{12}}{\sin 2 \theta_{13}-\sin 2 \theta_{12}-\sin 2 \theta_{23}} \\
& -\frac{\left[\left(\sigma_{\mathrm{II}}-\sigma_{\mathrm{I}}\right) \sin 2 \theta_{13}-\left(\sigma_{\mathrm{III}}-\sigma_{\mathrm{I}}\right) \sin 2 \theta_{12}\right] \sec 2 \varphi}{\sin 2 \theta_{13}-\sin 2 \theta_{12}-\sin 2 \theta_{23}} \\
\sigma_{2}= & \frac{-\sigma_{\mathrm{I}} \sin 2\left(\theta_{13}-\theta_{12}\right)+\sigma_{\mathrm{II}} \sin 2 \theta_{13}-\sigma_{\mathrm{III}} \sin 2 \theta_{12}}{\sin 2 \theta_{13}-\sin 2 \theta_{12}-\sin 2 \theta_{23}} \\
& +\frac{\left[\left(\sigma_{\mathrm{II}}-\sigma_{\mathrm{I}}\right) \sin 2 \theta_{13}-\left(\sigma_{\mathrm{III}}-\sigma_{\mathrm{I}}\right) \sin 2 \theta_{12}\right] \sec 2 \varphi}{\sin 2 \theta_{13}-\sin 2 \theta_{12}-\sin 2 \theta_{23}} .
\end{aligned}
$$

In the formula, $\theta_{23}=\theta_{13}-\theta_{12}$.

Formulas (12), (13), and (14) are the basic expressions for calculating the magnitude and direction of principal stresses. It is generally considered that $\sigma_{1}$ is the maximum principal stress, so the $\varphi$ value must satisfy the inequality derived from formula (10) and formula (11) and $\sigma_{1}-\sigma_{2}>0$ on the basis of satisfying (14):

$$
\frac{\left(\sigma_{\mathrm{I}}-\sigma_{\mathrm{II}}\right) \sec 2 \varphi}{1-\cos 2 \theta_{12}+\sin 2 \theta_{12} \tan 2 \varphi}>0 .
$$

When the angles between the normal vectors $n_{\mathrm{I}}$ and $n_{\mathrm{II}}$, and the angles between the normal vectors $n_{\mathrm{II}}$ and $n_{\mathrm{III}}$ are both $45^{\circ}$ angle, it can be calculated according to the following simplified formula.

$$
\begin{aligned}
\sigma_{1} & =\frac{\sigma_{\mathrm{I}}+\sigma_{\mathrm{III}}}{2}+\frac{\sqrt{2}}{2} \sqrt{\left(\sigma_{\mathrm{I}}-\sigma_{\mathrm{II}}\right)^{2}+\left(\sigma_{\mathrm{II}}-\sigma_{\mathrm{III}}\right)^{2}}, \\
\sigma_{2} & =\frac{\sigma_{\mathrm{I}}+\sigma_{\mathrm{III}}}{2}-\frac{\sqrt{2}}{2} \sqrt{\left(\sigma_{\mathrm{I}}-\sigma_{\mathrm{II}}\right)^{2}+\left(\sigma_{\mathrm{II}}-\sigma_{\mathrm{III}}\right)^{2}}, \\
\tan 2 \varphi & =\frac{\sigma_{\mathrm{I}}+\sigma_{\mathrm{III}}-2 \sigma_{\mathrm{II}}}{\sigma_{\mathrm{I}}-\sigma_{\mathrm{III}}} .
\end{aligned}
$$

From the above three formulas, the magnitude and direction of the two principal stresses in the horizontal plane can be obtained by solving the normal stress in three different directions in the same horizontal plane. Finally, according to the distribution of the intermediate principal stress, the in situ stress distribution of the measuring points can be obtained.

\section{Acoustic Emission Test of Rock}

5.1. Geological Conditions of Mining Area. The mine has more than 90 years of mining history. In recent years, the

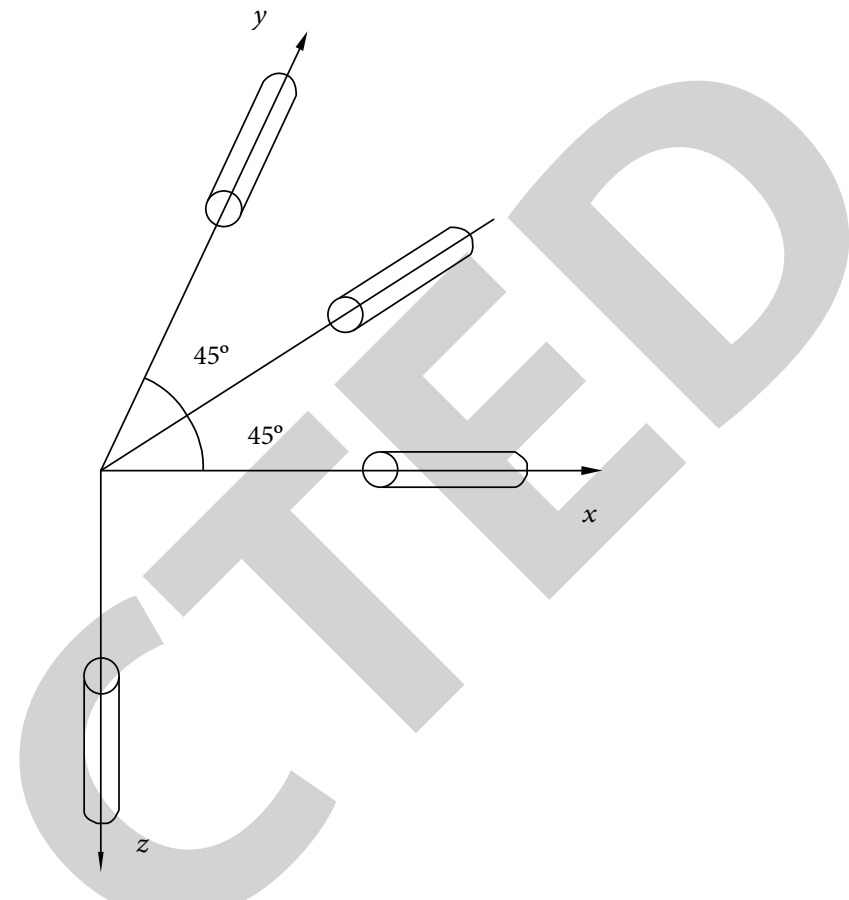

FIGURE 5: The schematic diagram of coring direction.

activity of ground pressure in the mining area has increased significantly, which has threatened the safety of mine production to a certain extent. A large number of mined-out areas, structural activities of the mining area, and structural characteristics of the rock mass have varying degrees of influence on the ground pressure activities in the mining area. The strata in the mining area are mainly the Quaternary modern slope deposits, residual deposits, and alluvial deposits, which are located at the end of the Gukeng anticline of the northwestern wing of the anticlinal incline to the South West. The direction of the strata in the area varies with the structural position. Fold axial mostly appears in the direction of the northeast-southwest and near the north-south direction. Tendency and inclination have greatly changed. There are a lot of faults, joints, and fissures in the rock group, which becomes the space of deformation compression. The middle section of the mining area is mainly distributed in the weathered layer and the tectonic development section. Because of the high weathering degree and structural development, the main structure of the rock mass is mainly cracked blocks or fragments, which are locally mixed with mud, and the bearing capacity of the structure is low.

5.2. Field Coring. In this experiment, the core is drilled at the depth of about $500 \mathrm{~m}$ in the middle part of the mining area. The axial direction of the core is $90^{\circ}$ vertical to the ground, and the horizontal direction is $225^{\circ}, 270^{\circ}$, and $315^{\circ}$. The diameter of the core is about $50 \mathrm{~mm}$. The schematic diagram of coring direction and the coring on the spot are shown in Figures 5 and 6.

5.3. Sample Processing. In order to ensure the integrity and homogeneity of the rock, 16 specimens with near wave velocity were selected from 47 processed metamorphic sandstone 


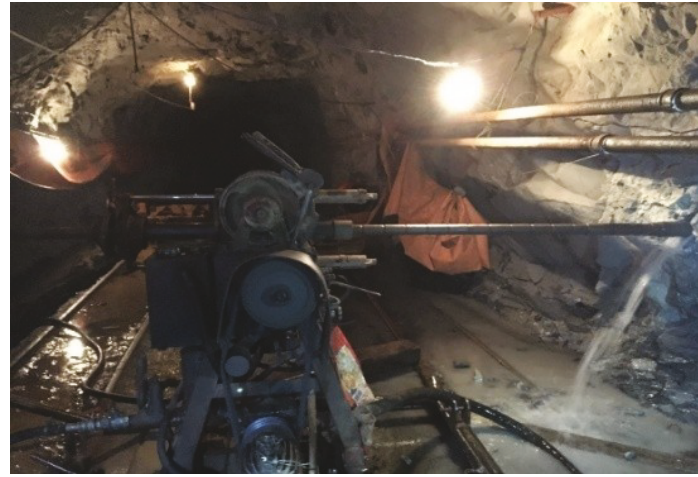

FiguRE 6: Coring on the site.

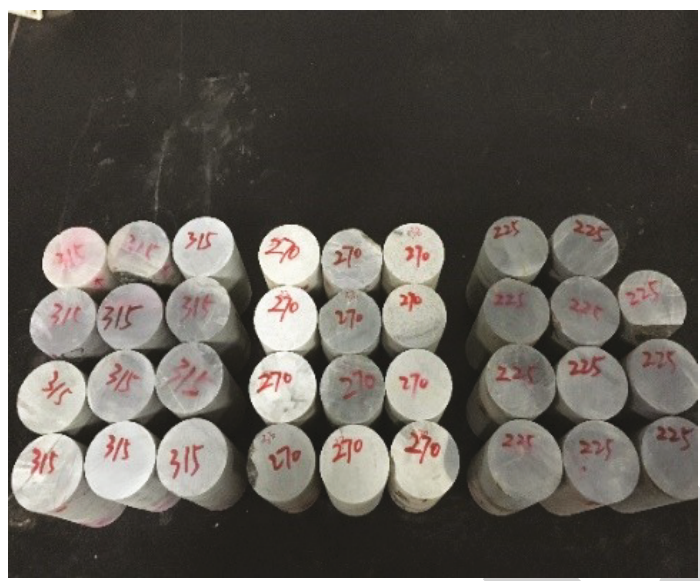

FIGURE 7: Some processed samples.

samples. The specimen is a cylindrical specimen that accords with the test procedure, and the ratio of height to diameter is about $2: 1$. Part of the sample is shown in Figure 7 . The specific information of the sample is shown in Table 1.

5.4. Test Instrument and Parameter Setting. The indoor acoustic emission test needs to use the RMT-150C rock mechanics test system (Figure 8(a)) and SAEU2S full waveform multi-channel acoustic emission detector (Figure 8(b)) to carry out the uniaxial loading test and acoustic emission signal acquisition. The two systems can collect and record the changes of basic variables and parameters in the test process and automatically generate the relationship diagram of each parameter.

The acoustic emission test is completed at the rate of $0.002 \mathrm{~mm} / \mathrm{s}$ under the displacement loading. The acoustic emission test system uses a resonant U-type probe with a center frequency of $1000 \mathrm{kHz}$. The probe is placed in the central position of the specimen. In order to ensure the success rate of the acquisition, two probes were used to collect data simultaneously. The complete channel of data acquisition was selected as the sample for data analysis. Acoustic emission parameters are shown in Table 2.

5.5. Determination of Kaiser Point. In this experiment, the influence of other factors on the determination of the Kaiser
TABLE 1: Sample information of the acoustic emission test.

\begin{tabular}{lcccc}
\hline \multirow{2}{*}{ Azimuth } & $\begin{array}{c}\text { Sample } \\
\text { number }\end{array}$ & $\begin{array}{c}\text { Sample size } \\
\text { Height } \\
(\mathrm{mm})\end{array}$ & $\begin{array}{c}\text { Diameter } \\
(\mathrm{mm})\end{array}$ & $\begin{array}{c}\text { Axial velocity } \\
\text { value }\left(\mathrm{m} \cdot \mathrm{s}^{-1}\right)\end{array}$ \\
\hline \multirow{3}{*}{ Horizontal } & $225^{\circ}-1$ & 102.56 & 54.00 & 4102 \\
direction $225^{\circ}$ & $225^{\circ}-2$ & 102.60 & 55.28 & 4104 \\
& $225^{\circ}-3$ & 102.40 & 55.00 & 4096 \\
& $225^{\circ}-4$ & 101.10 & 55.04 & 4044 \\
\hline \multirow{3}{*}{ Horizontal } & $270^{\circ}-1$ & 101.70 & 53.44 & 3767 \\
direction 270 & $270^{\circ}-2$ & 103.00 & 53.74 & 3433 \\
& $270^{\circ}-3$ & 101.48 & 53.50 & 3383 \\
& $270^{\circ}-4$ & 102.06 & 53.40 & 3645 \\
\hline Horizontal & $315^{\circ}-1$ & 102.76 & 54.02 & 3806 \\
direction $315^{\circ}$ & $315^{\circ}-2$ & 102.40 & 53.74 & 3657 \\
& $315^{\circ}-3$ & 102.02 & 54.00 & 4251 \\
& $315^{\circ}-4$ & 103.30 & 54.02 & 3973 \\
\hline \multirow{3}{*}{ Vertical } & $90^{\circ}-1$ & 99.96 & 49.04 & 3832 \\
direction $90^{\circ}$ & $90^{\circ}-2$ & 100.02 & 48.98 & 3804 \\
& $90^{\circ}-3$ & 100.00 & 49.00 & 4167 \\
\hline & $90^{\circ}-4$ & 100.50 & 49.00 & 4188 \\
\hline
\end{tabular}

point is not considered. Tests were carried out in accordance with the experimental standard of rock uniaxial compression. Using the above rock acoustic emission testing equipment, the processed 16 samples were tested to obtain the acoustic emission test signal. The $\mathrm{db} 3$ wavelet base is selected by using MATLAB software, and the acoustic emission ringing counting time sequence is denoised by the fixed threshold method. Based on the data after the noise reduction, the cumulative ringing count rate of acoustic emission is calculated and the cumulative ringing count rate-time-stress curve is plotted. The tangent intersection point is obtained by the conventional tangent method, and the point is approximated as the Kaiser point.

The G-P algorithm is used to calculate the ringing count relevant fractal dimension of the whole acoustic emission process. According to the process of the G-P algorithm, the relevant fractal dimension is affected by the reconstructed phase space dimension $m$. Taking sample 270-2 as an example, the change trend of phase space dimension and relevant fractal dimension is calculated, as shown in Figure 9. The change gradient of the relevant fractal dimension is relatively stable after the phase space dimension is taken as 4 . It is shown that the sample has a good fractal characteristic when the embedded dimension is 4 , so $m=4$. When calculating the relevant fractal dimension, the parameters obtained by the acoustic emission test are taken as a time varying sequence and the capacity of the sequence is 1024 that $n=1024$.

The fractal dimension-time-stress relationship of each sample is calculated by the G-P algorithm. The cumulative ringing count rate-time-stress curve and the corresponding correlation dimension-time-stress curve of each specimen are shown in Figure 10. The minimum point 

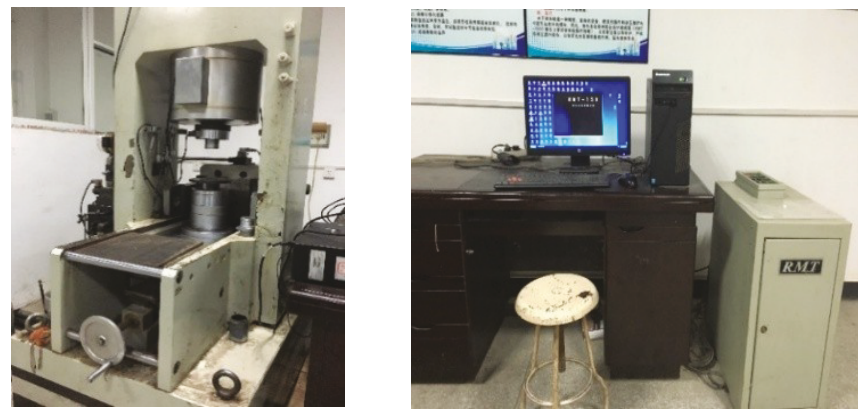

(a) RMT-150C rock mechanics test system

FIgURE 8: Test instrument.

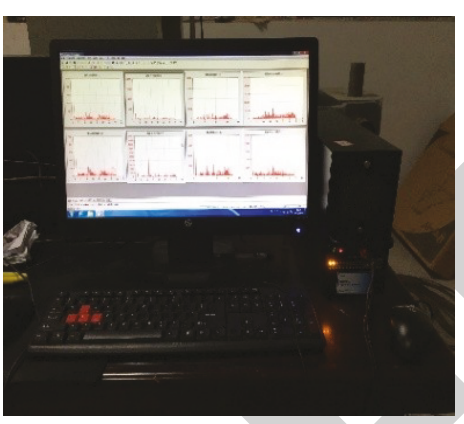

(b) Acoustic emission acquisition system

TABle 2: Acoustic emission acquisition parameter setting.

\begin{tabular}{lccccc}
\hline Threshold value & Preamplifier gain & Lower limit of analog filter & Upper limit of analog filter & Sampling rate & Sampling length \\
\hline $40 \mathrm{~dB}$ & $40 \mathrm{~dB}$ & $100 \mathrm{KHz}$ & $3 \mathrm{MHz}$ & $1 \mathrm{MSPS}$ & $2 \mathrm{k}$ \\
\hline
\end{tabular}

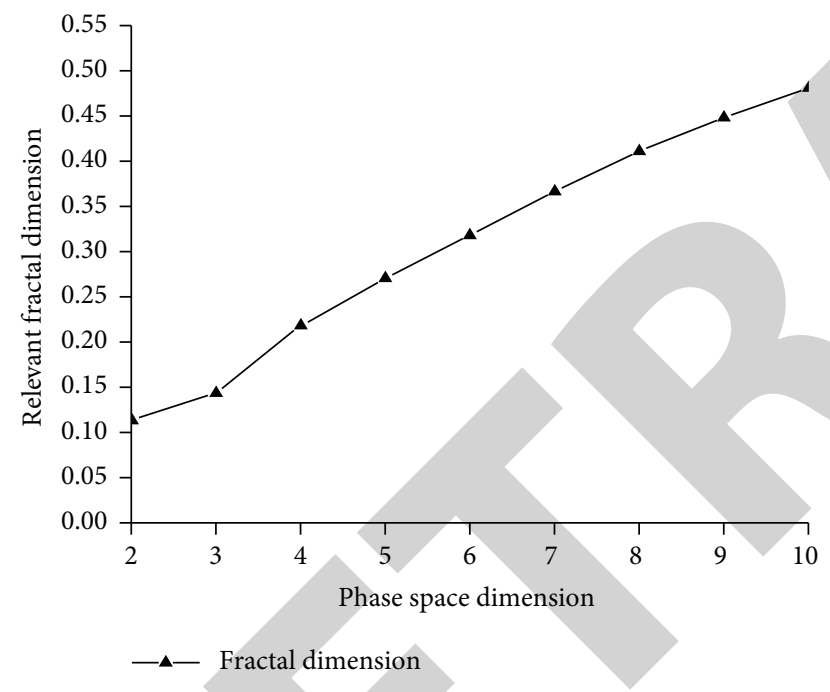

Figure 9: Relevant fractal dimension-phase space dimension relation curve.

of the fractal dimension is read over the approximate Kaiser point time range, where point $P$ is the lowest point, which is the Kaiser point. The corresponding stress value at this point is the original rock stress in the axial direction of the sample value. The stress value of each sample is shown in Table 3.

\section{Analysis of In Situ Stress in Mining Area}

6.1. Magnitude of In Situ Stress in Mining Area. The existence of vertical stress is related to tectonic activity, overlying strata thickness, temperature, water pressure, and so on. The gravity of overlying strata is the main influencing factor. A wide range of worldwide statistical data shows that in the depth range of $25 \sim 2700 \mathrm{~m}, \sigma_{v}$ is approximately equivalent to the average bulk density and $\gamma$ is equal to $27 \mathrm{kN} / \mathrm{m}^{3}$ calculated gravity $\gamma H$. The height of overlying strata in the middle section of mining is about $500 \mathrm{~m}$, so the estimated vertical stress $\sigma_{G}$ in the middle section is

$$
\sigma_{G}=\gamma H=0.027 \times 500=13.5 \mathrm{MPa} .
$$

The vertical stress value of acoustic emission measurement is $11.73 \mathrm{MPa}$, which accords with the law of overlying strata.

The stress values of the three horizontal directions are $\sigma_{\mathrm{I}}=9.27 \mathrm{MPa}, \sigma_{\mathrm{II}}=17.25 \mathrm{MPa}$, and $\sigma_{\mathrm{III}}=18.13 \mathrm{MPa}$. Put them into the following formula:

$$
\begin{aligned}
\sigma_{1} & =\frac{\sigma_{\mathrm{I}}+\sigma_{\mathrm{III}}}{2}+\frac{\sqrt{2}}{2} \sqrt{\left(\sigma_{\mathrm{I}}-\sigma_{\mathrm{II}}\right)^{2}+\left(\sigma_{\mathrm{II}}-\sigma_{\mathrm{III}}\right)^{2}} \\
& =\frac{9.27+18.13}{2}+\frac{\sqrt{2}}{2} \sqrt{(9.27-17.25)^{2}+(17.25-18.13)^{2}} \\
& =19.38 \mathrm{MPa}, \\
\sigma_{2} & =\frac{\sigma_{\mathrm{I}}+\sigma_{\mathrm{III}}}{2}-\frac{\sqrt{2}}{2} \sqrt{\left(\sigma_{\mathrm{I}}-\sigma_{\mathrm{II}}\right)^{2}+\left(\sigma_{\mathrm{II}}-\sigma_{\mathrm{III}}\right)^{2}} \\
& =\frac{9.27+18.13}{2}-\frac{\sqrt{2}}{2} \sqrt{(9.27-17.25)^{2}+(17.25-18.13)^{2}} \\
& =8.02 \mathrm{MPa} .
\end{aligned}
$$

Therefore, the maximum horizontal principal stress is 19.38 $\mathrm{MPa}$, the minimum horizontal principal stress is $8.02 \mathrm{MPa}$, and the vertical stress is $11.73 \mathrm{MPa}$. A large number of experimental results show that the maximum and minimum principal stresses in most parts of the world are distributed in the plane direction which is nearly horizontal. The ratio between the maximum horizontal principal stress $\sigma_{h \text {, max }}$ and the vertical stress $\sigma_{v}$ is generally in the range of 0.5 to 5.5 . Based on the measured data in the world, the ratio between the two horizontal principal stress $\sigma_{h \text {,av }}$ and the vertical principal stress $\sigma_{v}$ is in the range of 0.8 

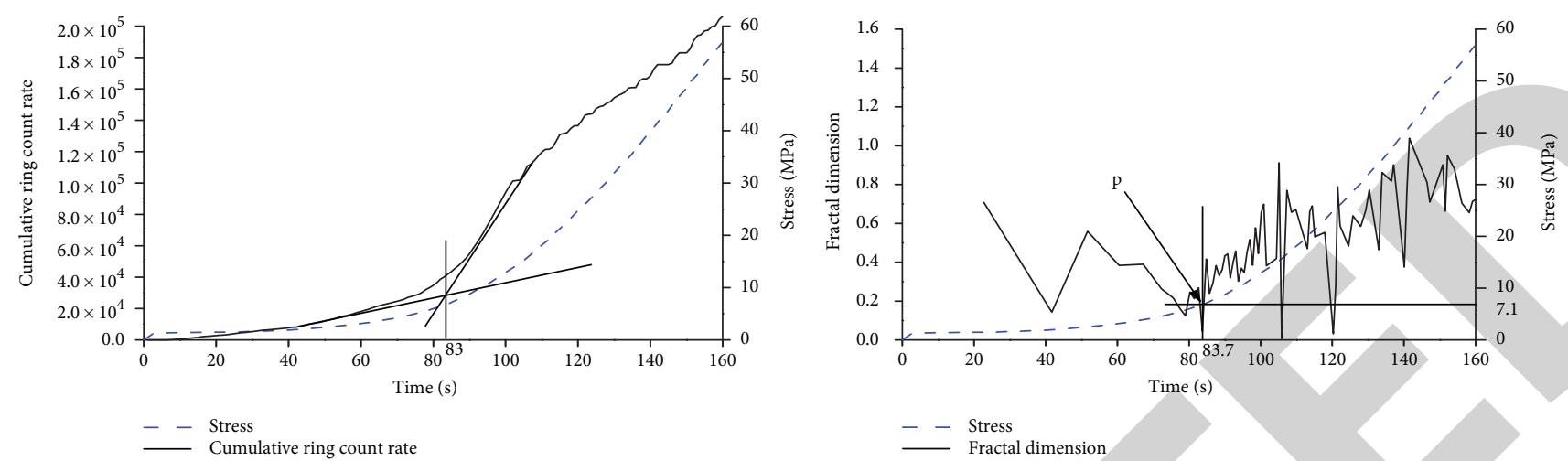

- - Stress

(a1) Sample 1 at $225^{\circ}$ in the horizontal direction
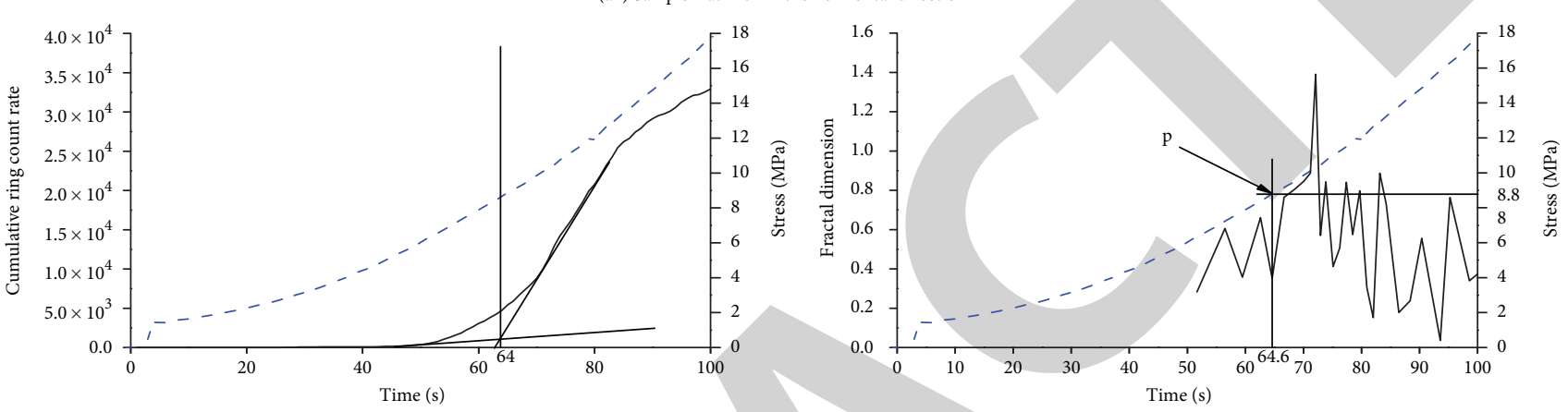

$\begin{array}{ll}-\ldots & \text { Stress } \\ - & \text { Cumulative ring count rate }\end{array}$

\begin{tabular}{ll}
$-\quad$ Stress \\
\hline & Fractal dimension
\end{tabular}

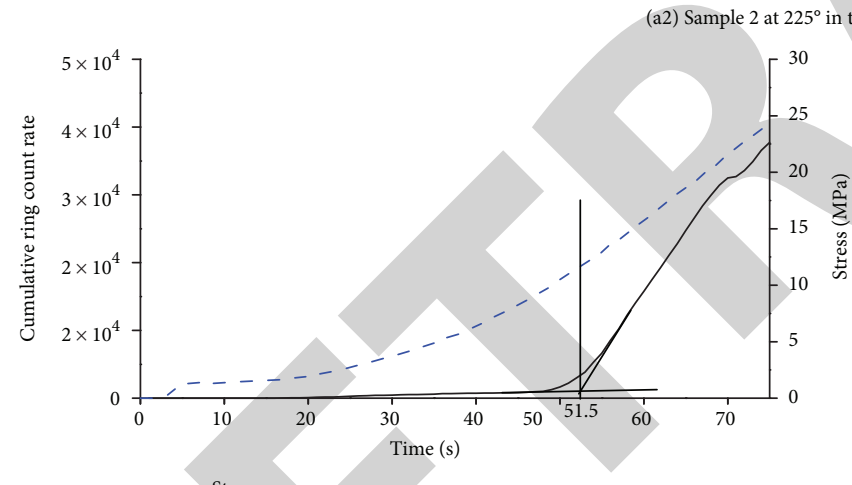

horizontal direction

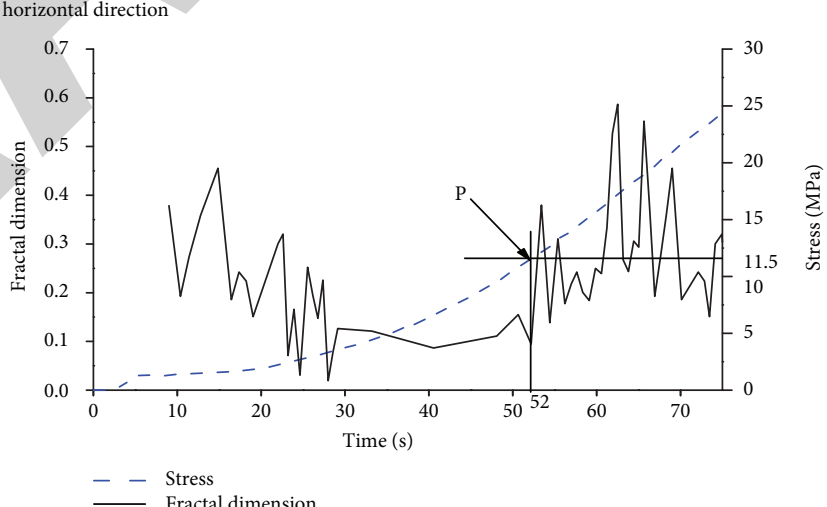

(a3) Sample 3 at $225^{\circ}$ in the horizontal direction
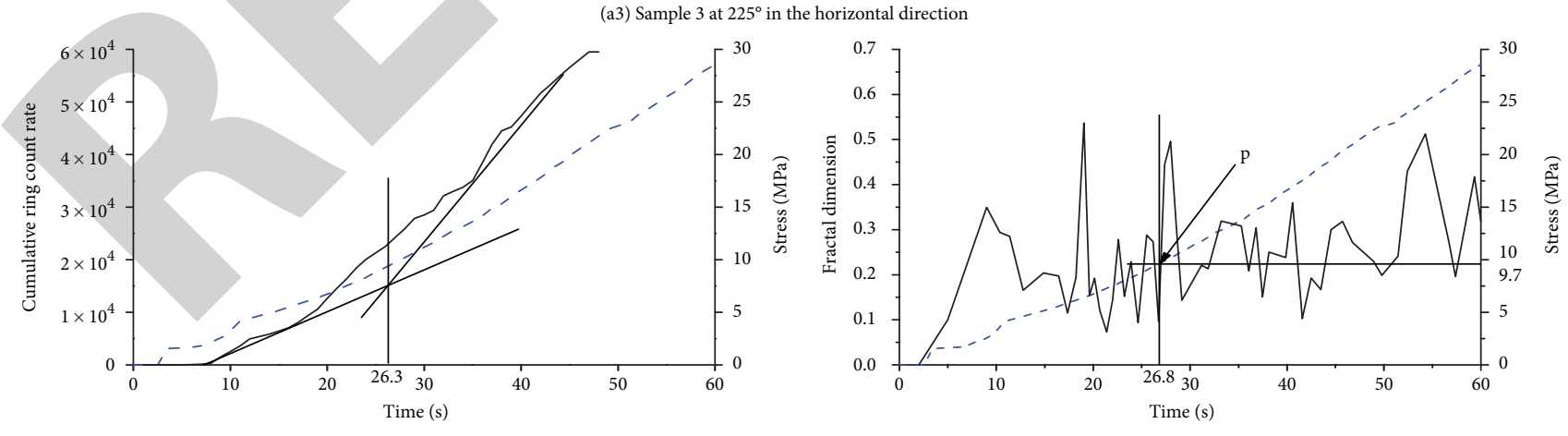

$\underline{-}-\begin{aligned} & \text { Stress } \\ & \text { Cumulative ring count rate }\end{aligned}$

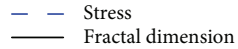

(a4) Sample 4 at $225^{\circ}$ in the horizontal direction

(a)

Figure 10: Continued. 

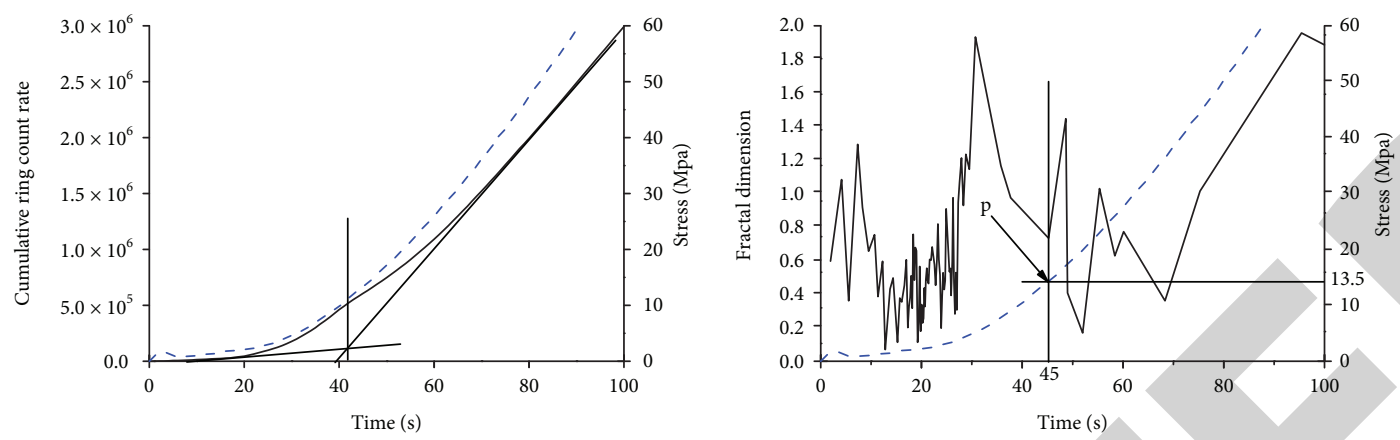

- - Stres

_ Cumulative ring count rate

- - - Stress

(b1) Sample 1 at $270^{\circ}$ in the horizontal direction
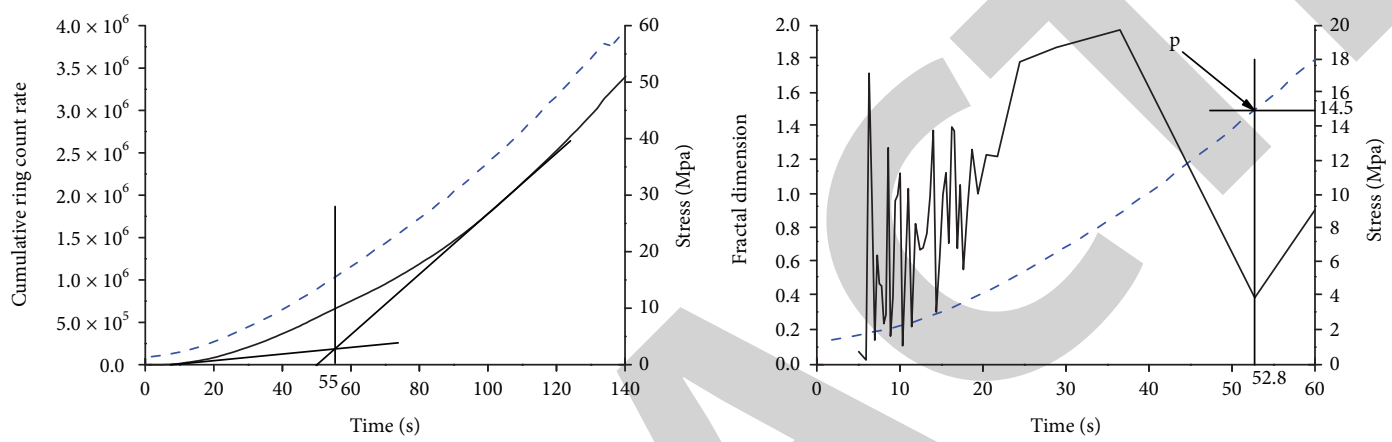

- - - Stress

_ Cumulative ring count rate

- -- Stress

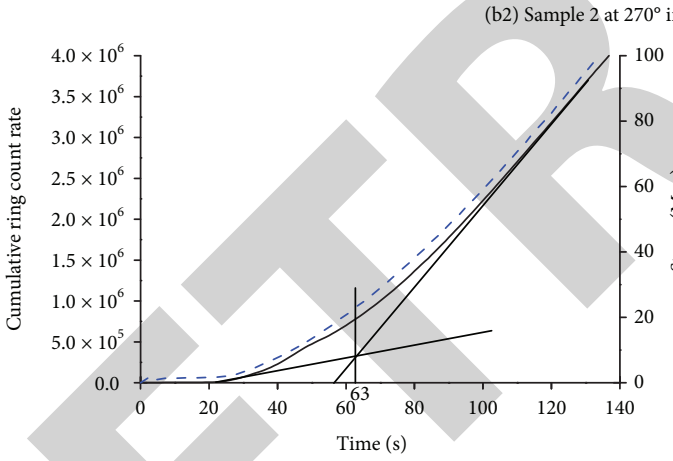

(b2) Sample 2 at $270^{\circ}$ in the horizontal direction
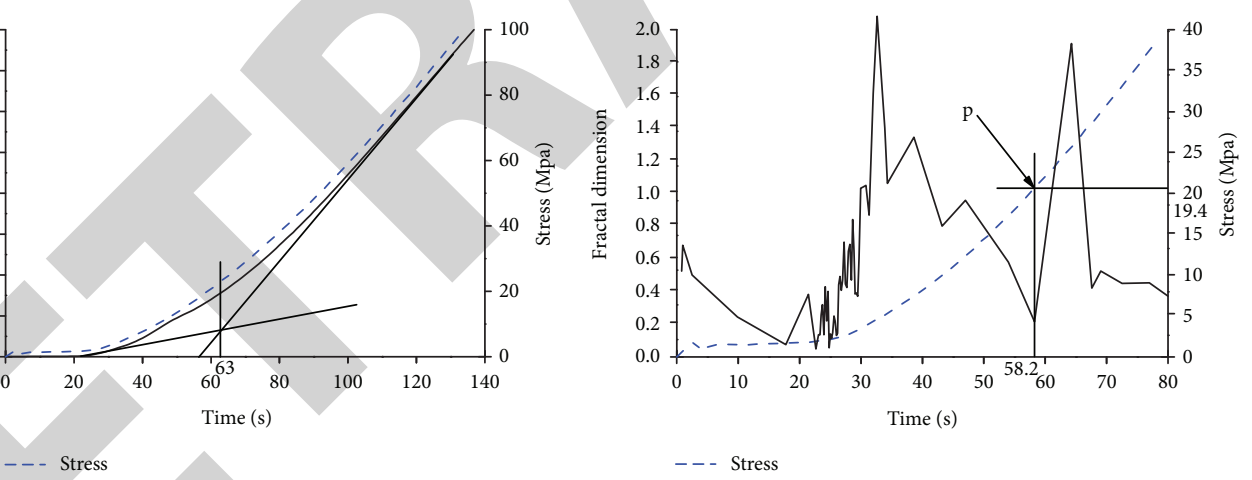

_ Cumulative ring count rate

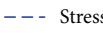

_ Fractal dimension

(b3) Sample 3 at $270^{\circ}$ in the horizontal direction
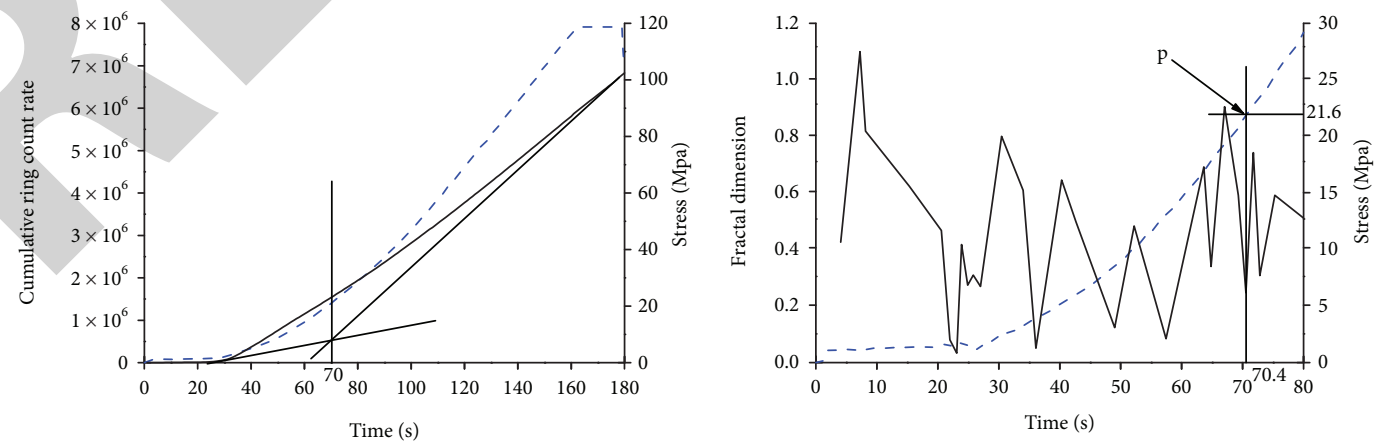

--- Stress

- - - Stress

(b4) Sample 4 at $270^{\circ}$ in the horizontal direction

(b)

Figure 10: Continued. 


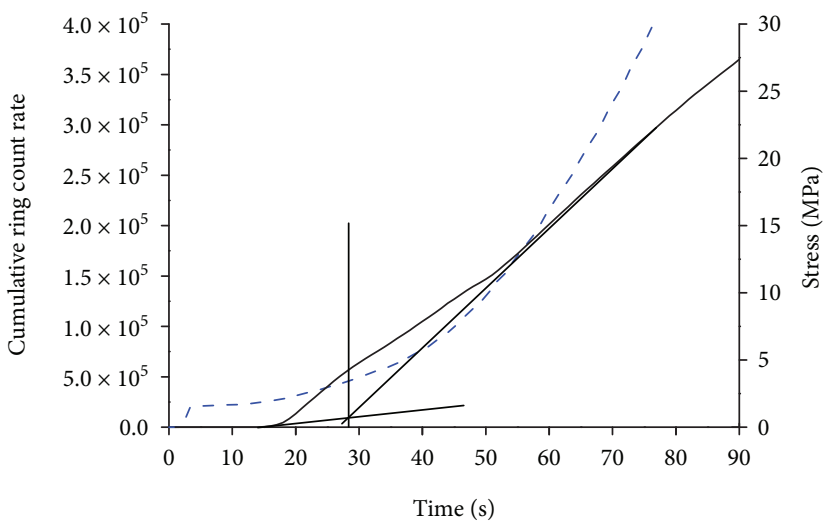

--- Stress

— Cumulative ring count rate

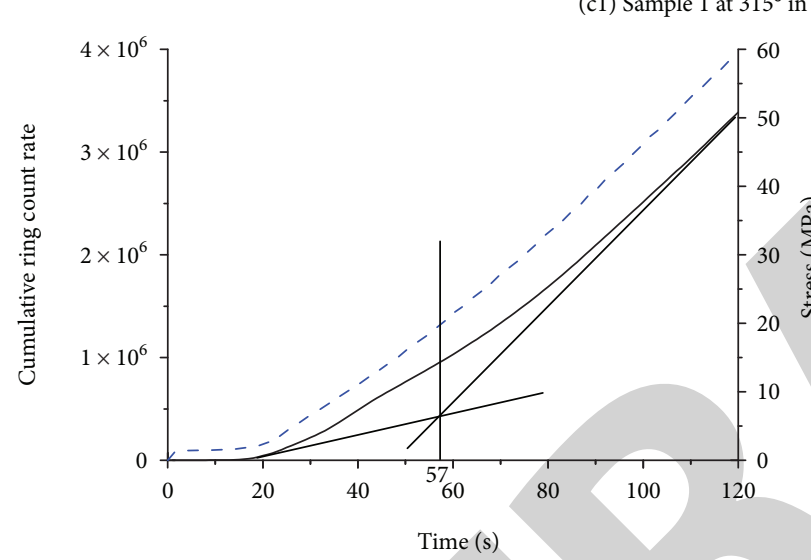

- - - Stress

— Cumulative ring count rate

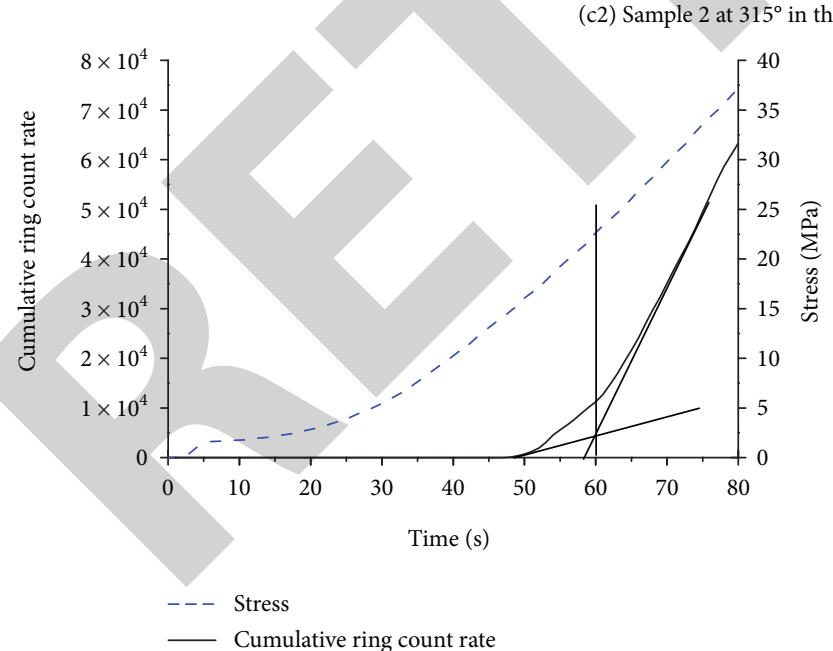

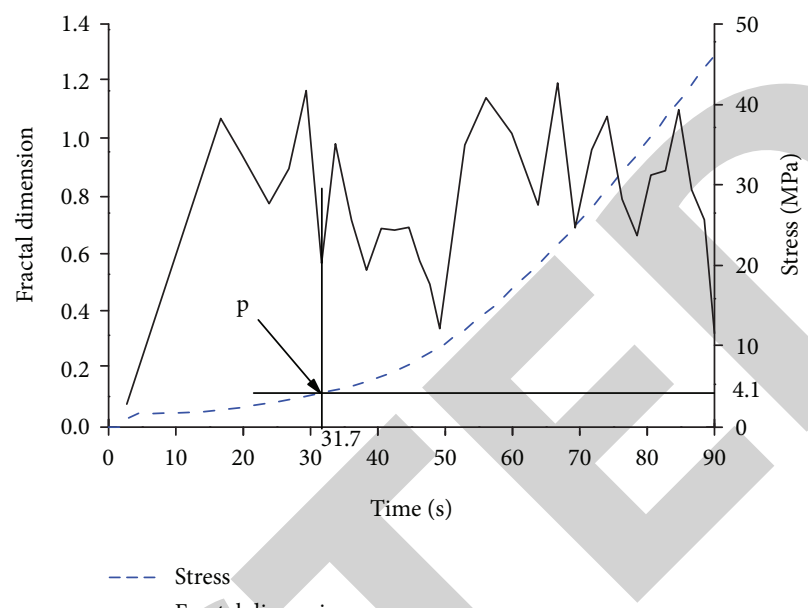

Fractal dimension

he horizontal direction

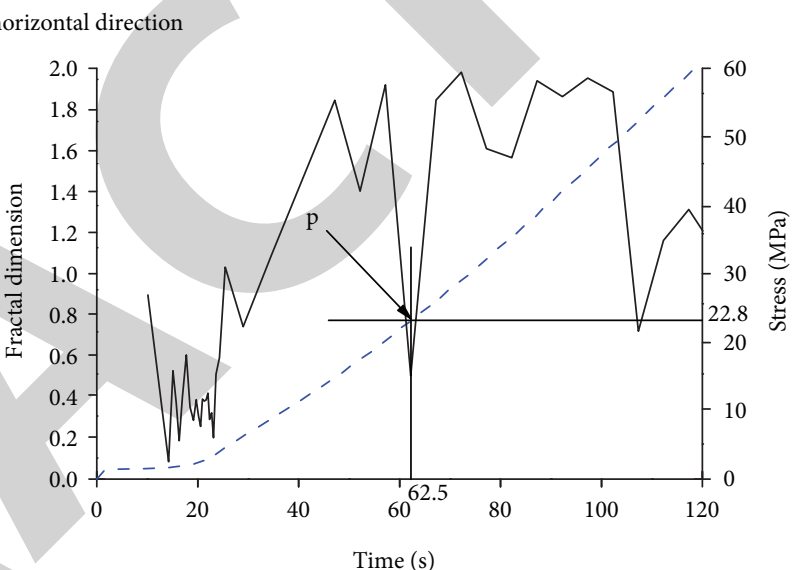

- - Stress

_ Fractal dimension

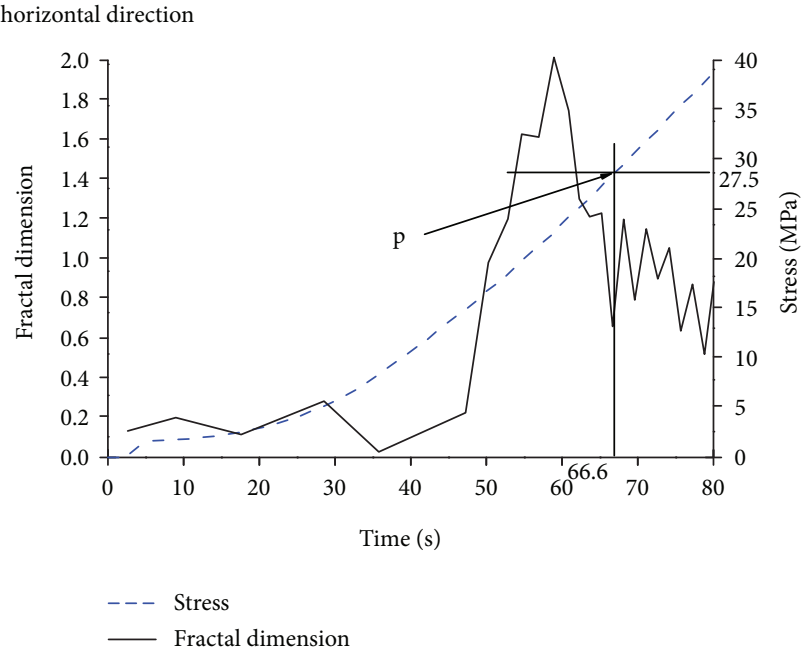

(c3) Sample 4 at $315^{\circ}$ in the horizontal direction

(c)

Figure 10: Continued. 

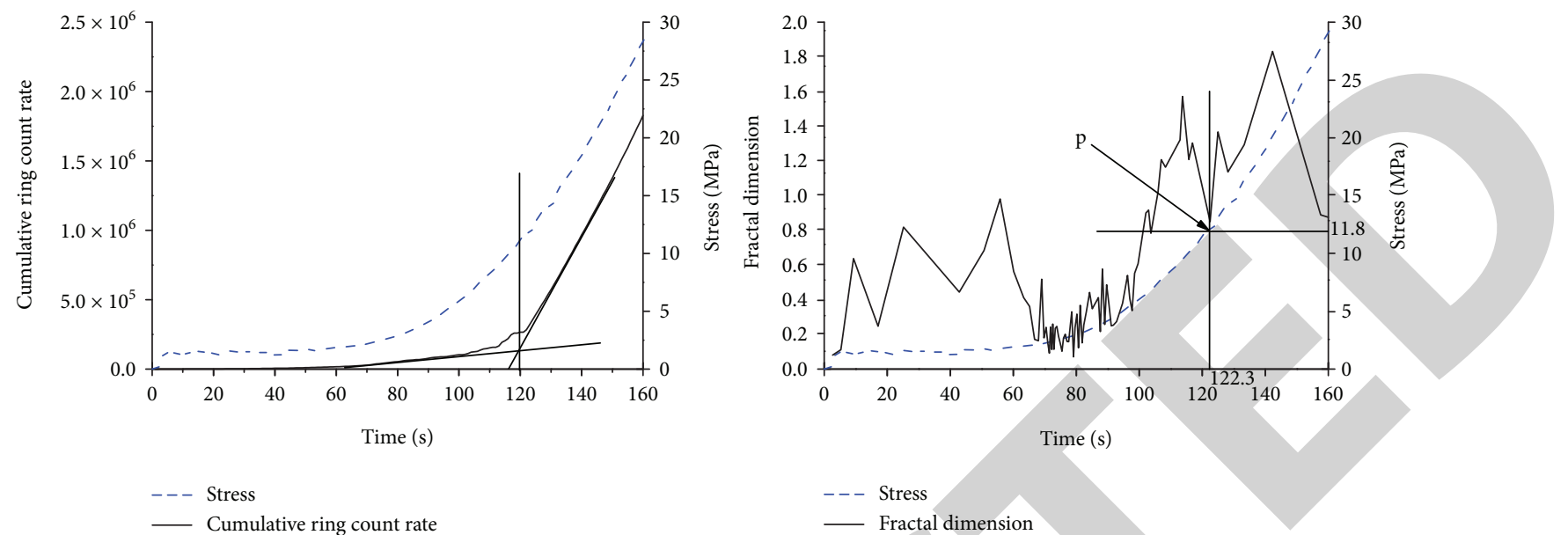

(d1) Sample 1 at $90^{\circ}$ in the horizontal direction
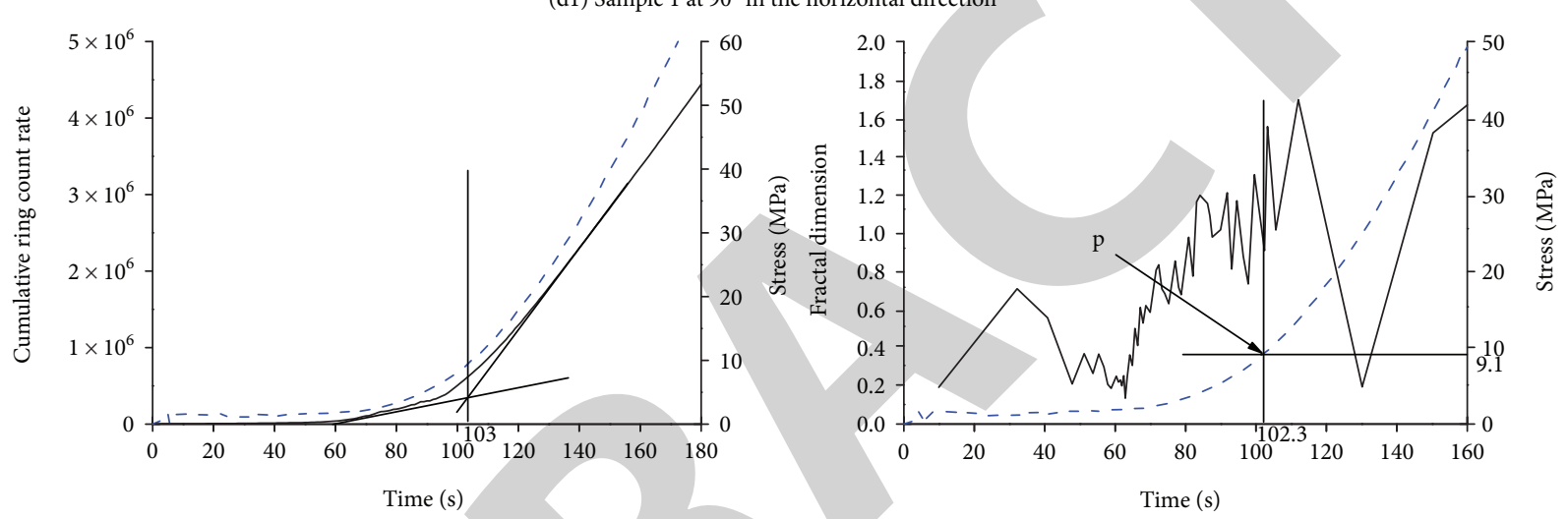

--- Stress

- Cumulative ring count rate

- - Stress

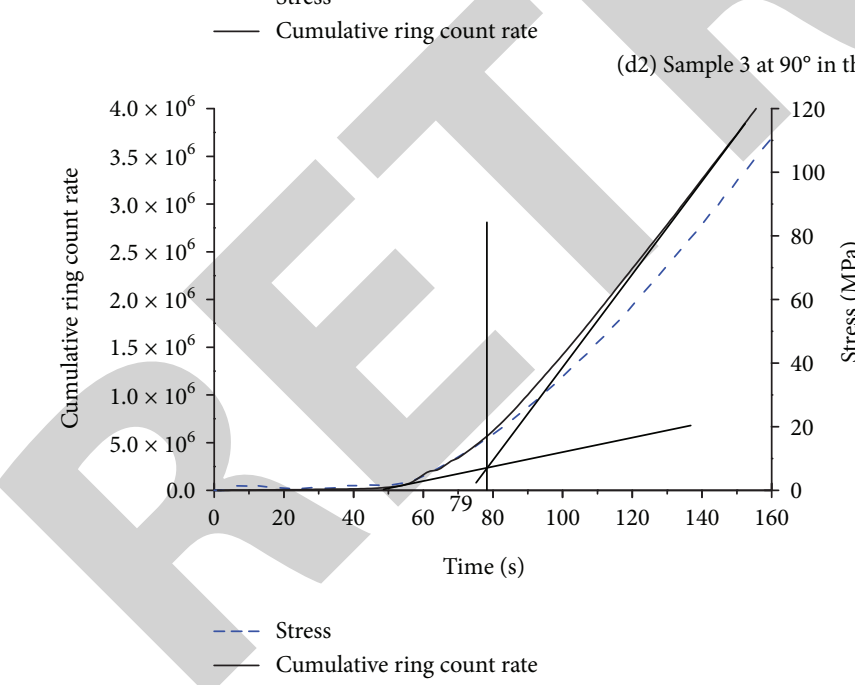

(d2) Sample 3 at $90^{\circ}$ in the horizontal direction

(d3) Sample 4 at $90^{\circ}$ in the horizontal direction

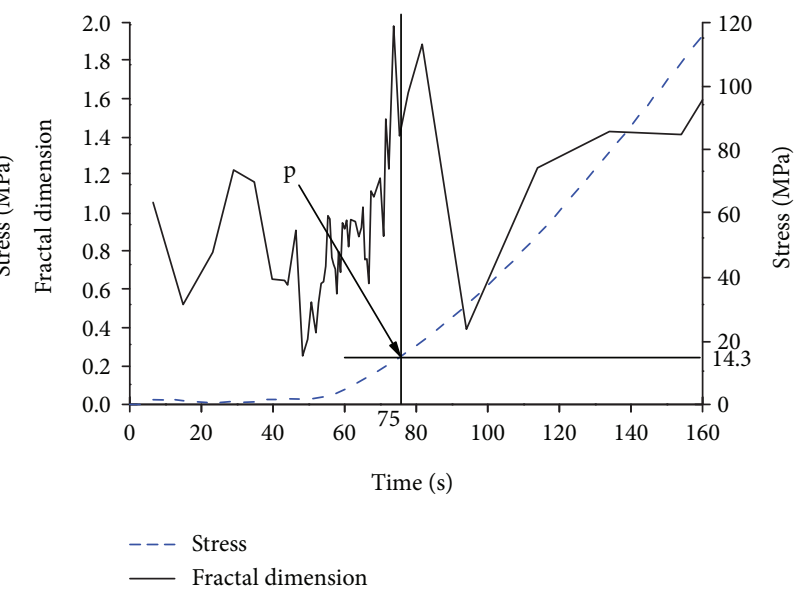

(d)

FIGURE 10: Interpretation of Kaiser point.

to 1.5 (see Table 4) [23]. According to the test results, the ratio of the mean value of the horizontal principal stress to the vertical stress is $\sigma_{h, \text { av }} / \sigma_{v}=1.17$ and the ratio of the maximum horizontal principal stress to the vertical principal stress is $\sigma_{h, \max } / \sigma_{v}=1.65$. They are basically consistent with the statistical laws of measured in situ stresses.
6.2. Direction of In Situ Stress in Mining Area. In order to understand the distribution of the in situ stress in the mining area and provide a basis for the ore body mining in the next stage, on the basis of the in situ stress data obtained by acoustic emission method, it is necessary to analyze the tectonic stress field of the study area combined with the 
TABLE 3: Kaiser point stress value of rock sample.

\begin{tabular}{lcccc}
\hline Azimuth & $\begin{array}{c}\text { Sample } \\
\text { number }\end{array}$ & $\begin{array}{c}\text { Stress value } \\
(\mathrm{MPa})\end{array}$ & $\begin{array}{c}\text { Average value } \\
(\mathrm{MPa})\end{array}$ & Remarks \\
\hline & $225^{\circ}-1$ & 7.1 & & \\
Horizontal & $225^{\circ}-2$ & 8.8 & 9.27 & \\
direction $225^{\circ}$ & $225^{\circ}-3$ & 11.5 & & \\
& $225^{\circ}-4$ & 9.7 & & \\
\hline & $270^{\circ}-1$ & 13.5 & & \\
Horizontal & $270^{\circ}-2$ & 14.5 & 17.25 & \\
direction $270^{\circ}$ & $270^{\circ}-3$ & 19.4 & & \\
& $270^{\circ}-4$ & 21.6 & & \\
\hline & $315^{\circ}-1$ & 4.1 & & \\
Horizontal & $315^{\circ}-2$ & 22.8 & 18.13 & \\
direction $315^{\circ}$ & $315^{\circ}-3$ & - & & Failure \\
& $315^{\circ}-4$ & 27.5 & & \\
\hline & $90^{\circ}-1$ & 11.8 & & \\
Vertical & $90^{\circ}-2$ & - & & \\
direction $90^{\circ}$ & $90^{\circ}-3$ & 9.1 & & \\
& $90^{\circ}-4$ & 14.3 & & \\
\hline
\end{tabular}

TABLE 4: Relationship between the average principal stress and the vertical principal stress in different countries in the world [23].

\begin{tabular}{lcccc}
\hline Country name & \multicolumn{5}{c}{$\begin{array}{c}\sigma_{h, \mathrm{av}} / \sigma_{v}(\%) \\
0.8 \sim 1.2\end{array}$} & $>1.2$ & $\sigma_{h, \text { max }} / \sigma_{v}$ \\
\hline China & 32 & 40 & 28 & 2.09 \\
Australia & 0 & 22 & 78 & 2.95 \\
Canada & 0 & 0 & 100 & 2.56 \\
America & 18 & 41 & 41 & 3.29 \\
Norway & 17 & 17 & 66 & 3.56 \\
Sweden & 0 & 0 & 100 & 4.99 \\
South Africa & 41 & 24 & 35 & 2.50 \\
Former Soviet Union & 51 & 29 & 20 & 4.30 \\
Other areas & 37.5 & 37.5 & 25 & 1.96 \\
\hline
\end{tabular}

geological structure and then infer the direction of the in situ stress in the mining area.

Fold is the bending deformation of the rock stratum under stress. It is the tectonic trace preserved by the crustal rock deformation and fracture caused by the tectonic stress. It is the most common geological structure in the crust. The direction of the in situ stress can be inferred by studying the direction of folds and strata in the mining area. According to the geological report of the mine, it is known that the fold structure in the mining area is mainly the end of the Gukeng anticline of the northwestern wing of the anticlinal incline to the South West. The direction of the strata in the area varies with the structural position. The axial direction is $40 \sim 60$ degrees, and the axis direction of the fold is parallel to the direction of the minimum principal stress, so it is perpendicular to the direction of the maximum principal stress. It is speculated that the direction of the maximum principal stress in the mining area is approximately $\mathrm{N}$ $\left(30^{\circ} \sim 40^{\circ}\right) \mathrm{E}$; the direction of the minimum principal stress is $\mathrm{N}\left(50^{\circ} \sim 60^{\circ}\right) \mathrm{W}$.

6.3. Comprehensive Analysis of In Situ Stress in Mining Area. In general stress distribution in the mining area, the maximum principal stress is $19.38 \mathrm{MPa}$ in the direction of $\mathrm{N}\left(30^{\circ} \sim 40^{\circ}\right) \mathrm{E}$, the minimum principal stress is $8.02 \mathrm{MPa}$ in the direction of $\mathrm{N}\left(50^{\circ} \sim 60^{\circ}\right) \mathrm{W}$. The maximum principal stress and the minimum principal stress are both generally in the horizontal plane. The direction of the intermediate principal stress is vertically downward and the size is $11.73 \mathrm{MPa}$.

The maximum principal stress is $19.38 \mathrm{MPa}$. According to the relevant criteria, $0 \sim 10 \mathrm{MPa}$ is a low stress zone, $10 \sim 18 \mathrm{MPa}$ is a medium stress zone, and $18 \sim 30 \mathrm{MPa}$ is a high stress area; more than $30 \mathrm{MPa}$ is an ultrahigh stress area [24]. Therefore, the in situ stress in the mining area belongs to the high stress field.

The maximum horizontal principal stress in the mining area is about 1.44 times that of the self-weight stress, indicating that the stress field in the mining area is dominated by the horizontal tectonic stress rather than the self-weight stress.

The ratio between the maximum horizontal principal stress and the minimum horizontal principal stress is 2.42 , which shows a large difference between the two. The difference between the maximum principal stress and the minimum principal stress will lead to a larger shear stress in the rock mass. When the shear stress in the rock mass is greater than the shearing strength of the rock mass, the fracture will occur. This provides favorable stress conditions for the formation of faults, joints, and fissures in the mining area.

\section{Conclusion}

Through the analysis and research of the various characteristic curves of rock acoustic emission, the relationship curves of cumulative ringing count rate-time-stress curve and fractal dimension-time-stress curve of acoustic emission are analyzed and processed. A simple and accurate interpretation method of in situ stress measurement by using the Kaiser effect of rock is proposed.

In this experiment, a fractal theory was used to interpret the acoustic emission test results, and the relevant fractal dimension of rock acoustic emission is calculated. According to the G-P algorithm, the fractal dimension-time-stress curves of the samples were obtained. Combined with the traditional mapping method, the Kaiser point of rock acoustic emission is more accurately interpreted, reducing the interference of human subjective factors.

According to the measured results and the comprehensive analysis of the geological structure in the mining area, the main distribution of the in situ stress field is obtained. The maximum principal stress is $19.38 \mathrm{MPa}$ in the direction of $\mathrm{N}\left(30^{\circ} \sim 40^{\circ}\right) \mathrm{E}$, and the minimum principal stress is $8.02 \mathrm{MPa}$ in the direction of $\mathrm{N}\left(50^{\circ} \sim 60^{\circ}\right) \mathrm{W}$. The direction of the intermediate principal stress is vertically downward with a value of $11.73 \mathrm{MPa}$. 
The magnitude and distribution of in situ stress in the mine derived from the method presented in this study are consistent with the distribution statistical law of the measured in situ stress field in the world.

\section{Data Availability}

The data used to support the findings of this study are available from the corresponding author upon request.

\section{Conflicts of Interest}

The authors declare that they have no conflicts of interest.

\section{Acknowledgments}

The study is supported by the National Natural Science Foundation (no. 51764013), the Science and Technology Support Plan Project of Jiangxi Provincial Science and Technology Department (Grant nos. 20161BBG70075 and 20143ACG70010), and the Key Research Project of Science and Technology of Jiangxi Provincial Education Department (Grant no. GJJ160592).

\section{References}

[1] C. Zhang, X. T. Feng, and H. Zhou, "Estimation of in situ stress along deep tunnels buried in complex geological conditions," International Journal of Rock Mechanics and Mining Sciences, vol. 52, pp. 139-162, 2012.

[2] J. Zhao, D. Tang, H. Xu et al., "Characteristic of in situ stress and Its control on the coalbed methane reservoir permeability in the eastern margin of the Ordos Basin, China," Rock Mechanics and Rock Engineering, vol. 49, no. 8, pp. 33073322, 2016.

[3] J. S. Bell and S. E. Grasby, "The stress regime of the Western Canadian sedimentary basin," Geofluids, vol. 12, no. 2, 165 pages, 2012.

[4] H. P. Kang, J. Lin, and X. Zhang, "Research and application of in-situ stress measurement in deep mines," Chinese Journal of Rock Mechanics and Engineering, vol. 26, no. 5, pp. 929-933, 2007.

[5] E. Komurlu, A. Kesimal, and R. Hasanpour, "In situ horizontal stress effect on plastic zone around circular underground openings excavated in elastic zones," Geomechanics and Engineering, vol. 8, no. 6, pp. 783-799, 2015.

[6] P. Lin, H. Liu, and W. Zhou, "Experimental study on failure behaviour of deep tunnels under high in-situ stresses," Tunnelling and Underground Space Technology, vol. 46, pp. 28-45, 2015.

[7] M. F. Cai, M. C. He, and D. Y. Liu, Rock Mechanics and Engineering, Science Press, Beijing, China, 2002.

[8] A. Mazaira and P. Konicek, "Intense rockburst impacts in deep underground construction and their prevention," Canadian Geotechnical Journal, vol. 52, no. 10, pp. 1426-1439, 2015.

[9] P. Yan, W. B. Lu, M. Chen, Y. G. Hu, C. B. Zhou, and X. X. Wu, "Contributions of in-situ stress transient redistribution to blasting excavation damage zone of deep tunnels," Rock Mechanics and Rock Engineering, vol. 48, no. 2, pp. 715-726, 2015.
[10] S. J. Miao, M. F. Cai, Q. F. Guo, and Z. J. Huang, "Rock burst prediction based on in-situ stress and energy accumulation theory," International Journal of Rock Mechanics and Mining Sciences, vol. 83, pp. 86-94, 2016.

[11] M. F. Cai and L. Qiao, The Theory and Techniques of Crustal Stress Measurement, Science Press, Beijing, China, 1995.

[12] J. A. Hudson, F. H. Cornet, and R. Christiansson, "ISRM suggested methods for rock stress estimation-part 1: strategy for rock stress estimation," International Journal of Rock Mechanics and Mining Sciences, vol. 40, no. 7-8, pp. 991-998, 2003.

[13] X. G. Meng et al., "Acoustic emission ground stress field testing and mechanism of deformation and instability in deep soft rock roadway," Journal of China Coal Society, vol. 41, no. 5, pp. 1078-1086, 2016.

[14] S. Kramadibrata, G. M. Simangunsong, K. Matsui, and H. Shimada, "Role of acoustic emission for solving rock engineering problems in Indonesian underground mining," Rock Mechanics and Rock Engineering, vol. 44, no. 3, pp. 281-289, 2011.

[15] Y. X. Li and B. C. Dong, "In-situ stress measurement of reservoir using Kaiser effect of rock," Chinese Journal of Rock Mechanics and Engineering, vol. 28, no. S1, pp. 2802-2807, 2009.

[16] Y. H. Lu, M. Chen, Y. Jin, W. Wu, J. Zhang, and Y. Li, “A new method for determination of geographic orientation of deep formation geostress," Chinese Journal of Rock Mechanics and Engineering, vol. 30, no. 2, pp. 233-237, 2011.

[17] Y. Kang, X. H. Li, Q. H. Wang, and Y. D. Jiang, "Research on in-situ stress measurement and rockburst forecast in tunnels," Rock and Soil Mechanics, vol. 26, no. 6, pp. 959-963, 2005.

[18] Q. Chen, B. L. Zhu, and H. T. Hu, "Experimental research on measurement of in-situ stress field by Kaiser effect," Chinese Journal of Rock Mechanics and Engineering, vol. 25, no. 7, pp. 1371-1376, 2006.

[19] G. M. Boyce, A Study of the Acoustic Emission Response of Various Rock Types, Drexel University, 1981.

[20] A. Lavrov, "The Kaiser effect in rocks principles and stress estimation techniques," International Journal of Rock Mechanics and Mining Sciences, vol. 40, no. 2, pp. 151-171, 2003.

[21] H. T. Wang, X. F. Xian, G. Z. Yin, and J. Xu, “A new method of determining geostresses by the acoustic emission Kaiser effect," International Journal of Rock Mechanics and Mining Sciences, vol. 37, no. 3, pp. 543-547, 2000.

[22] P. Grassberger and I. Procaccia, "Characterization of strange attractors," Physical Review Letters, vol. 50, no. 5, pp. 346349, 1983.

[23] X. F. Yu, Preliminary Calculation of Geotechnical Mechanics and Mining in the Information Age, Science Press, Beijing, China, 1991.

[24] H. P. Kang, J. Lin, X. Zhang, and Y. Z. Wu, "In-situ stress measurements and distribution laws in Lu'an underground coal mines," Rock and Soil Mechanics, vol. 31, no. 3, pp. 827$831,2010$. 